\title{
Intelligent Cooperative Education Process Management Model on Cloud Computing Technology for Higher Education Institutes in Thailand
}

\author{
Suriya Pumchalerm, Prachyanun Nilsook, and Namon Jeerungsuwan
}

\begin{abstract}
The purposes of the research study were: 1) to analyze a research framework of intelligent cooperative education process management model on cloud computing technology for higher education institutes in Thailand, 2) to synthesize the mentioned model, 3) to design the model and 4) to evaluate the designed model. The study used qualitative and quantitative method. The opinions of 15 experts in cooperative education with information and communication technology experiences were the sample group. The research tool was an in-depth interview and an open-ended and closed-ended questionnaire with five-point rating scale. Mean $(\bar{x})$ and Standard Devision (S.D.) were used for the data analysis. The conceptual framework was used to design the intelligent cooperative education process management model on cloud computing technology. The design of the model was evaluated by 15 experts as most appropriate $\bar{x}=4.42$, S.D. $=0.51$ ).
\end{abstract}

Index Terms-Cooperative education, intelligent system, cloud computing.

\section{INTRODUCTION}

Education was the process in which helped each individual develop in many aspects [1]. Education with only studying the theoretical part would not enough to effectively develop the country. Experience in working was also another important reinforcement that helped combine skills, intellects, and knowledge of a person in order to improve his or her organization [2]. From the business organization's point of view, candidates who obtained any other skills, besides academic knowledge, were more preferable. The other skills preferred by the business organization were knowledge implementation, credibility, problem solving, self-improvement and moral ethical awareness. These skills could not be learned from any textbooks or papers. They were learned from practicing in real life, especially in a working context [3]. Applying and integrating the knowledge gained from classrooms with working experience in the business organizations created professional skills and selfimprovement skills [4]. The management of the course of cooperative education was more different than the management of the general courses. It was necessary to integrate all the needs of students, co-op supervisor, co-op coordinator and entrepreneur. Therefore, applying the

Manuscript received February 5, 2015; revised May 8, 2015.

The authors are with the Faculty of Technical Education, King Mongkut's University of Technology North Bangkok, Thailand (e-mail: pumchalerm@hotmail.com).
Information and Communication Technology (ICT) was an appropriate solution for managing cooperative education. It was also in accordance with the B.E. 2554 - 2564 Information and Communication Technology conceptual framework of the government or so-called "ICT 2020" which focused on using ICT to be Thailand's driving force for sustainable knowledge, intellect and the growing economy with equality. Implementing ICT to the cooperative education was also agreed with strategy Number 2 of the Ministry of Education in which it was promoting learning and teaching management using ICT in order to increase the effectiveness of the Thai educational system. The aim was to empower the citizens of the nation with emphasizing the learner development using ICT as an essential tool. This would help sustainably improve the country as a whole

\section{PuRPose OF THE STUDY}

1) To analyze a research framework of intelligent cooperative education process management model on cloud computing technology for higher education institutes in Thailand.

2) To synthesize intelligent cooperative education process management model on cloud computing technology.

3) To design intelligent cooperative education process management model on cloud computing technology.

4) To evaluate the design model for above.

\section{ReSEARCH Methodology}

The design of the model for intelligent cooperative education process management on cloud computing technology for higher education institutes in Thailand consisted of two phases as follows:

Phase 1: Reviewed papers, literature related studies and in-depth interview with experts to analyze and synthesize a research framework.

Phase 2: Design and evaluate the design of the model for intelligent cooperative education process management on cloud computing technology.

\section{A. Population and Sample}

Population of the study were experts specialised in both cooperative education and ICT in higher education institutions.

The sample group was the purposive sample group of 15 experts with three year experiences in both cooperative education and in ICT. 


\section{B. Tools}

Phase 1: In-depth interview with experts to synthesis process and model.

Phase 2: The open-ended and closed-ended question of a questionnaire with a five-point rating scale was used as a tool of the study. The design was appropriate for applying in model, in which 1 represented the least appropriate, 2 for scarcely appropriate, 3 for somewhat appropriate, 4 for highly appropriate and 5 for the most appropriate, respectively [5].

\section{Data Analysis}

Data gained from the expert evaluation on the design of model for intelligent cooperative educational process management on cloud computing technology were collected. Mean and Standard Devision were used to analyze the appropriateness of the design.

\section{RESULT}

Data synthesis led to create the conceptual framework of designing model. The conceptual framework consists of four components: 1) Stakeholder, 2) Cloud Computing Technology, 3) Intelligent System and, 4) Cooperative Education Process. Details are as following Fig. 1.

The synthesis of the characteristic of cooperative education process management with six prototype institutes about cooperative education in Thailand, shown in Table I.

\begin{tabular}{ccccccc} 
TABLE I: CHARACTERISTICS OF COOPERATIVE EDUCATION PROCESSES \\
MANAGEMENT \\
\hline \hline \multirow{3}{*}{ Process } & MUA & SUT & WU & RMUTT & KMUTNB & SPU \\
\cline { 2 - 7 } & {$[6]$} & {$[7]$} & {$[8]$} & {$[9]$} & {$[10]$} & {$[11]$}
\end{tabular}

\begin{tabular}{|c|c|c|c|c|c|c|}
\hline \multicolumn{7}{|l|}{ Pre-Operation } \\
\hline $\begin{array}{l}\text { 1. Pre-Cooperative } \\
\text { Resister }\end{array}$ & & $\checkmark$ & $\checkmark$ & & $\checkmark$ & $\checkmark$ \\
\hline $\begin{array}{l}\text { 2. Academic } \\
\text { Preparation }\end{array}$ & $\checkmark$ & & & $\checkmark$ & & $\checkmark$ \\
\hline & \multicolumn{5}{|c|}{ Information } & $\checkmark$ \\
\hline $\begin{array}{l}\text { 4. Announce Jobs to } \\
\text { Students }\end{array}$ & $\checkmark$ & & & & $\checkmark$ & $\checkmark$ \\
\hline $\begin{array}{l}\text { 5. Declaration of } \\
\text { Intention }\end{array}$ & & $\checkmark$ & $\checkmark$ & $\checkmark$ & $\checkmark$ & $\checkmark$ \\
\hline 6. Subject Register & & $\checkmark$ & $\checkmark$ & $\checkmark$ & $\checkmark$ & $\checkmark$ \\
\hline $\begin{array}{l}\text { 7. Qualification } \\
\text { Screening }\end{array}$ & $\checkmark$ & & & $\checkmark$ & & \\
\hline 8. Application & & $\checkmark$ & $\checkmark$ & & & \\
\hline 9. Quality of Jobs & $\checkmark$ & & & & & \\
\hline \multicolumn{7}{|l|}{ Guarantee } \\
\hline 11. Pairing & & $\checkmark$ & $\checkmark$ & $\checkmark$ & $\checkmark$ & $\checkmark$ \\
\hline 12. Select Student & & & $\checkmark$ & $\checkmark$ & & $\checkmark$ \\
\hline 13. Selected Results & $\checkmark$ & $\checkmark$ & $\checkmark$ & $\checkmark$ & $\checkmark$ & \\
\hline \multirow[b]{2}{*}{ Process } & \multicolumn{6}{|c|}{ Institute } \\
\hline & MUA & SUT & WU & RMUTT & KMUTNB & SPU \\
\hline $\begin{array}{l}\text { 15. Meeting with } \\
\text { Student and Co-op } \\
\text { Supervisors }\end{array}$ & & & & & & $\checkmark$ \\
\hline $\begin{array}{l}\text { 16. Accident } \\
\text { Insurance }\end{array}$ & $\checkmark$ & & & & & \\
\hline 17. Define Jobs & & $\checkmark$ & $\checkmark$ & & & \\
\hline
\end{tabular}

Characteristics

18. Meeting with all Stakeholder

19. Assistance Document

20. Preparation

21. Training

Orientation

22. Students

Delivery

Operation

1. Entry Report of Students

2. Send Planning

3. Present Project Proposal

\begin{tabular}{lcccccc} 
4. Progress Report & $\checkmark$ & $\checkmark$ & $\checkmark$ & $\checkmark$ & $\checkmark$ & $\checkmark$ \\
5. Send Report & & $\checkmark$ & $\checkmark$ & & & \\
6. Supervising & $\checkmark$ & $\checkmark$ & $\checkmark$ & $\checkmark$ & $\checkmark$ & $\checkmark$ \\
7. Consulting & & & & & & $\checkmark$ \\
8. Present Training & $\checkmark$ & & & $\checkmark$ & $\checkmark$ & $\checkmark$ \\
9. Evaluation & $\checkmark$ & & & $\checkmark$ & $\checkmark$ & $\checkmark$ \\
\hline
\end{tabular}

Post-Operation

1. Student

Returning

2. Evaluation

3. Send Completion

Report

4. Seminar

5. Interview

6. Evaluation

Report

7. Collect

Evaluation

8. Feedback Report $\checkmark$

9. Post-Training

10. Contest Project

11. Save to Database

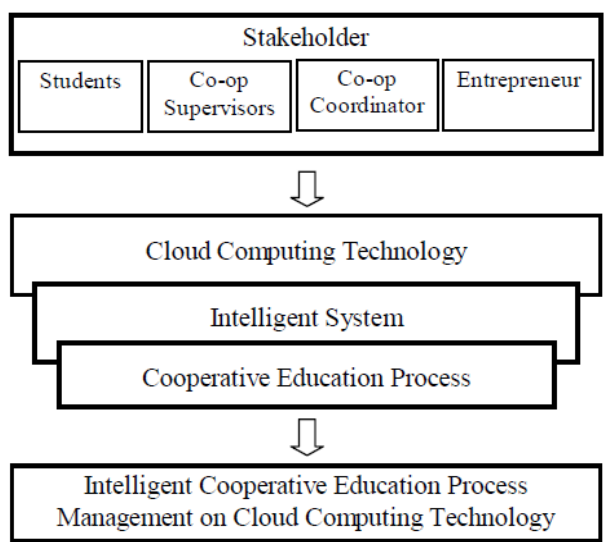

Fig. 1. Conceptual framework.

The synthesized found, intelligent cooperative education process management had three main-processes and each main-process had sub-processes as follows.

Pre-Operation had nine sub-processes: 1) Announce 2) Academic Preparation 3) Subject Register 4) Declaration of Intention 5) Qualification Screening 6) Pairing/Select 7) Announcement 8) Training Orientation and 9) Students Delivery. Operation had five sub-processes: 1) Entry Report of Students 2) Planning /Project Proposal 3) Progress Report 
4) Supervising and 5) Result of Training Presentation. Post-Operation had seven sub-processes: 1) Student Returning 2) Completion Report 3) Assessment 4) Post-Training 5) Outstanding Performance Selection 6) Evaluation Summary and 7) Feedback Report. Researchers took conceptual framework and synthesized cooperative education process to design the model. The result was the intelligent cooperative education process management model on cloud computing technology for higher education institutes in Thailand, shown on Fig. 2.

TABLE II: RESULTS OF THE MAIN COMPONENT

\begin{tabular}{lccc}
\hline \multicolumn{1}{c}{ Main component } & $\bar{x}$ & S.D. & appropriate \\
\hline Main component has four components & 4.26 & 0.45 & most \\
1) Stakeholder & & & \\
2) Cloud Computing Technology & & & \\
3) Intelligent System & & & \\
4) Cooperative Education Process & & & \\
\hline \hline
\end{tabular}

TABLE III: RESULTS OF THE SUB COMPONENT

\begin{tabular}{lccc}
\hline \hline \multicolumn{1}{c}{ Sub components } & $\bar{x}$ & S.D. & appropriate \\
\hline 1) Stakeholder has four components & 4.60 & 0.63 & most \\
1.1 Students & & & \\
1.2 Co-op Supervisors & & & \\
1.3 Co-op Coordinators & & & \\
1.4 Entrepreneur & 4.20 & 0.67 & highly \\
\hline 2) Intelligent system (Qualification & & & \\
Screening and Pairing/Select only) & & & \\
use intelligent agent technique has & & & \\
three features & & & \\
2.1 Adaption & & & most \\
2.2 Automation & & & \\
2.3 Interaction & 4.33 & 0.61 & \\
\hline 3) Cloud computing technology use & & & \\
- Software as a Service & & & \\
- Public Cloud & 4.86 & 0.35 & \\
\hline 4) Cooperative Education Process & & & \\
Management has three main step & & & \\
4.1) Pre-Operation) & & \\
4.2) Operation) \\
4.3) Post-Operation)
\end{tabular}

TABLE IV: RESULTS OF THE SUB STEPS

\begin{tabular}{llll}
\hline \hline $\begin{array}{c}\text { Sub step of cooperative education } \\
\text { process }\end{array}$ & $\bar{x}$ & S.D. & appropriate \\
\hline 1) Pre-Operation has nine sub steps & 4.53 & 0.51 & most \\
1.1 Announce & & & \\
1.2 Academic Preparation & & & \\
1.3 Subject Register & & & \\
1.4 Declaration of Intention & & & \\
1.5 Qualification Screening & & & \\
1.6 Pairing/Selection & & & \\
1.7 Announcement & $\bar{x}$ & S.D. & Appropriate \\
\hline \hline Sub step of cooperative education & & & \\
process & & & \\
\hline 1.8 Training Orientation & & \\
1.9 Students Delivery & & & \\
\hline 2) Operate has five sub steps & & \\
2.1 Entry Report to Students & & & \\
2.2 Planning /Project Proposal & & \\
2.3 Progress Report & & & \\
2.4 Supervising & & & \\
2.5 Result of Training Presentation & & & \\
\hline 3) Post-Operation has seven sub steps & 4.60 & 0.50 & \\
3.1 Student Returning & & & \\
3.2 Completion Report & & & \\
3.3 Assessment & & \\
3.4 Post-Training & & \\
3.5 Outstanding Performance & & \\
Selection & & & \\
3.6 Evaluation Summary & & \\
\hline \hline
\end{tabular}

The synthesised, processes worked on public cloud as a Software as a Service (Saas). The model would be considered in two processes: 1) Qualification Screening and 2) Pairing/Select only. The results were evaluated by 15 experts as detailed in the Table II and Table III.

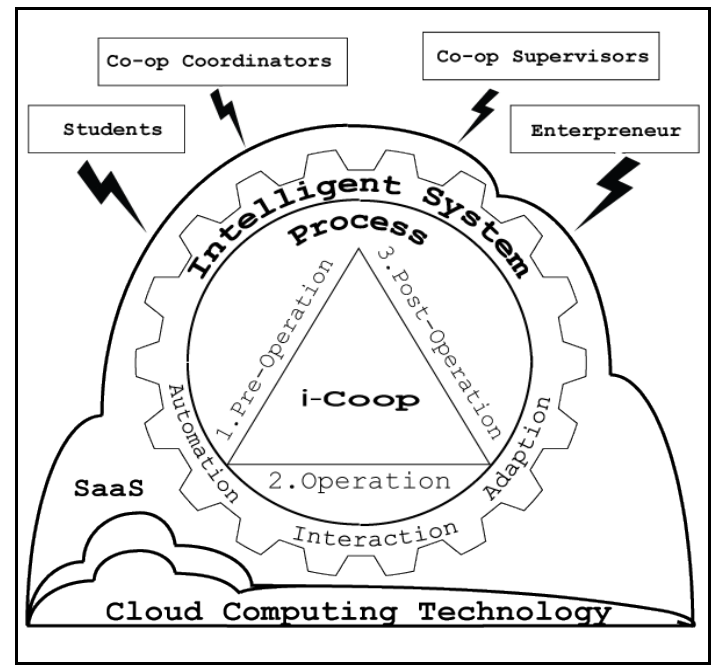

Fig. 2. Intelligent cooperative education process management model on cloud computing technology.

\section{DISCUSSION}

The result was evaluated by the experts on the design of the intelligent cooperative education process management model on cloud computing technology, Main component, was considered as most appropriate $(\bar{x}=4.26$, S.D. $=0.45)$. The average of four sub-components was considered as most appropriate ( $\bar{x}=4.49$, S.D. $=0.56$ ). The average of three sub-steps of cooperative education process was considered as most appropriate ( $\bar{x}=4.53$, S.D. $=0.54)$. Summary, in general experts was considered as most appropriate $(\bar{x}=4.42$, S.D. $=0.51$ ). The attitude towards the design of the model evaluated by the experts showed that the designs and patterns of the intelligent cooperative education process management on cloud computing for higher education institute in Thailand could be practically. The design constructed in the study also conformed to the three aspects appeared in WiL Pagoda Model of Chinintorn and Plaimas [12], in which each aspect comprises of six tiers. The first tier of each aspect represents the cooperation between people who involve with work-integrated learning educational management. Moreover, the information technology applied to the design constructed in this study was based on the research framework of Thangkabutra [13]. This study all process work on cloud computing technology to operate and cooperate in information connection consistent with research of Rodmunkong and Wannapiroon [14], led to the standards and achieves the quality practices and procedures of cooperative education required by the Office of Higher Education Commission and Thai Association for Cooperative Education [15].

\section{SOME COMMON MistaKeS}

Cloud computing technology is the new technology for 
education in Thailand and it have very important, because it is an information technology emphasizing on flexible expansion [16], user can access every time, everywhere and access from various devices through web browser on internet provider [17]. In this study focus on Software as a service. SaaS can be use for base operating platform to share data, calculations and service user under information technology [18]. However, the researcher has developed the information system on cloud computing to become more intelligent by applying agent technology of which properties were relevant to Document Agent version 1.0 of Object Management Group (OMG) [19]. The three unique properties that agents possess include: 1) Automation, 2) Interaction, and 3) Adaption.

\section{ACKNOWLEDGMENT}

The research work was supported by Faculty of Technical Education, Vocational Education Technology Research Center and Innovation and Technology Research Center at the Science and Technology Research Institute, King Mongkut's University of Technology North Bangkok.

\section{REFERENCES}

[1] Office of Higher Education Commission, Framework of the second 15 year long range plan on higher education of Thailand (2008-2022), Bangkok: Office of the Permanent Secretary, Ministry of Education, 2008 .

[2] B. A. Calway, What has Work-Integrated Learning Learned? - A WIL Philosophy, Lily Dale: Swinburne University of technology, 2005.

[3] World Association of Cooperative Education, Membership Directory, Boston: World Association of Cooperative Education (WACE), 2000.

[4] W. Srisa-Arn. (June 2014). Students' quality developing with cooperative education. [Online]. Available: http://www.tace.or.th

[5] R. A. Likert, "Technique for the measurement of attitudes," Archives of Psychology, vol. 140, no. 55, 1932.

[6] Office of Higher Education Commission and Thai Association for Cooperative education, Standards and Quality Assurance Cooperative Education, Bangkok: Thai Association for Cooperative Education, 2010.

[7] The Center for Cooperative Education and Career Department, Cooperative Education Handbook, Bangkok: Suranary Technology University, 2012.

[8] The Center for Cooperative Education and Career Department, Cooperative Education Hand Book, Bangkok: Walairuk University, 2013.

[9] Office of Cooperative Education, Cooperative Education Hand Book, Bangkok: Rajamangala University of Technology Thanyaburi, 2012.

[10] Thai-German Dual Education and e-Learning Development Institute, Cooperative Education Hand Book, Bangkok: King Mongkut's University of Technology North Bangkok, 2013.

[11] Cooperative Education and Professional Department Center, Cooperative Education Handbook, Bangkok: Sripatum University, 2012.

[12] P. Chinintorn et al., Learning and Teaching Management Guideline for Learning and Working Integration (Work-Integrated-Learning: WiL) in Thai Higher Education, Bangkok: WiL Working Group Thailand Project Report, 2010.

[13] T. Thungkabutra, "Remote supervision pattern development for students on internship," in Proc. NEC2012 Integrating ASEAN Online Learning, Bangkok, 2012, pp. 147-151.

[14] T. Rodmunkong and P. Wannapiroon, "The design of cloud computing management information system accordance with Thai qualifications framework for higher education," International Journal of e-Education, e-Business, e-Management and e-Learning, vol. 3, no. 3, pp. 214-218, 2013.
[15] Subcommittees promote the development of cooperative education, Plan Promotes Cooperative Education in Higher Education Institutions (BE.2551-2555), Bangkok: Office of Higher Education Commission and Thai Association for Cooperative Education, 2007.

[16] B. P. Rimal, E. Choi, and I. Lumb, "A taxonomy and Survey of cloud computing systems," in Proc. Fifth International Joint Conference on INC, IMS and IDC, 2009, pp. 44-51.

[17] C. N. Liao, I. L. Chih, and Y. K. Fu. "Cloud computing: A concept framework for knowledge management system," Human Systems Management, vol. 30, no. 3, pp. 137-143, 2011.

[18] H. Singh, A. Bhiskar, and J. Singh. "Innovative ICT through cloud computing," The IUP Journal of Computer Sciences, vol. 7, no. 1, pp. 45-46, 2013

[19] Object Management Group, Agent Technology, Green Paper, OMG Document, Version 1.0, Needham: Agent Platform Special Interest Group, 2000.

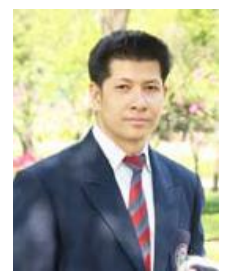

Suriya Pumchalerm is studying for the doctor of philosophy in information and communication technology for education, Faculty of Technical Education, King Mongkut's University of Technology North Bangkok, Thailand. He received his master's degree in information technology from Sripatum University in 2002, the bachelor's degree in computer science from Suan Sunandha Rajabhat University in 1999 and the bachelor's degree in technology and communications for education from Sukhothai Thammathirat Open University in 2008. His main interests include web technology, cloud computing information system for education. He is currently a full time lecturer at the Department of Business Information System, Faculty of Administration, Southeast Bangkok College, Bangkok, Thailand.

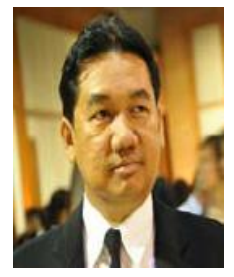

Prachyanun Nilsook is an associate professor at Division of Information and Communication Technology for Education, Faculty of Technical Education, King Mongkut's University of Technology North Bangkok (KMUTNB), Thailand. He received the B.Ed. degree in audio-visual education, from Faculty of Education, Ramkhamhang University, Thailand in 1989. He obtained his M.Ed. degree in educational technology from Faculty of Education, Srinakarinwirot University, Thailand in 1995, and received the Ph.D. degree in educational communications and technology from Faculty of Education, Chulalongkorn University in 2001. From 2001 to present, he works in the field of information and communication technology in education. He has experience in many positions such as the dean, the faculty of technical education, Samutsongkhram Technical Collage and the director of Vocational Education Technology Research Center. He received National Teachers Award of the Year in Higher Education 2004 from National Teacher Council, Ministry of Education, and Thailand. He is a membership of Professional Societies in Association for Educational Technology of Thailand (AETT).

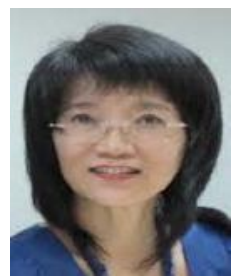

Namon Jeerungsuwan is a Ph.D. She is currently a full time associate professor at the Department of Technological Education, Faculty of Technical Education, King Mongkut's University of Technology North Bangkok, Thailand. She has held a position of the director of Ph.D. program in information and communication technology for education since 2011 . She was the head of the Department of Educational Technology, KMUTNB, during 2002-2006. She received her doctoral degree in instructional design and development from University of South Alabama and her master's degree in educational media from Western Oregon University. She also received the award of the Royal Thai Government Scholarship and the award of Kappa Delta Phi during she was pursuing the doctoral degree in the USA. Her past experience included the director of Online Learning Center, KMUTNB. Currently, she is the executive committee of the e-Learning Association of Thailand, the Educational Technology Association of Thailand, and the associate editor of International Journal of Technology, Knowledge, and Society, and the member of IEEE society. 